\title{
Evaluation of Noise Pollution and Effects on Workers during Wheat Processing
}

\author{
${ }^{* 1}$ IB. IBRAHIM, AS. AREMU ${ }^{2 *}$, KR. AJAO ${ }^{1}$, AT. OJELABI ${ }^{3}$
}

\author{
Department of Mechanical Engineering, University of Ilorin, Nigeria \\ ${ }^{2}$ Department of Water Resources \& Environmental Engineering, University of Ilorin, Nigeria ${ }^{3}$ Centre for Deaf and Supportive Services, \\ University of Ilorin, Nigeria. \\ "Corresponding author: E- mail: aremu_adeniyi@yahoo.com
}

KEYWORDS: Wheat processing, noise, machines, workers, audiometric examination

\begin{abstract}
This study assessed the intensity and likely effects of noise on workers during wheat processing. Noise measurements were taken using HD600 sound level meter. Subjective assessment of the effects of noise was undertaken using semi structured questionnaire. Also audiometric test was conducted on workers using AD229e diagnostic audiometer. The results of the study show that during wheat processing operations, the noise level in the factory ranges between $56.0 \mathrm{~dB}(\mathrm{~A})$ and $100.9 \mathrm{~dB}(\mathrm{~A})$. Also, only $25.6 \%$ of all the readings was below the specified limit of $85 \mathrm{~dB}(\mathrm{~A})$. Workers are also observed to have certain forms of physiological and psychological disorders related to noise. The audiometric test results revealed that $33 \%$ of the examined workers have defect in their left or right ear. Based on these results, WHO Class-5 hearing protector is recommended to be worn by workers in the processing sections while room acoustics should be upgraded to absorb some sounds transmitted to offices. ( ) JASEM
\end{abstract}

http://dx.doi.org/10.4314/jasem.v18i4.6

Introduction: Exposure to high occupational noise which results in health risks is commonly encountered in a variety of industrial processes. Its effects depend not only on the intensity, but also on exposure time, frequency and the type of noise (Ahmed et al., 2001). According to the World Health Organization (WHO, 2011), high levels of noise may lead to speech interference, reduction in productivity, high blood pressure, hearing defects, health disorders, sleep interference, cardiovascular effects, loss of concentration and absenteeism, and fatigue.

Therefore, regulations limiting the levels of noise in which industrial workers are exposed to have been instituted in many places. For example in Nigeria, the National Environmental Standards and Regulations Enforcement Agency mandates industrial employers to limit factory noise to a value less than $85 \mathrm{~dB}(\mathrm{~A})$ for an 8-hour period (NESREA, 2009) as prolonged exposure to continuous sound in excess of this limit is potentially dangerous. A study (Harmadji and Kabullah, 2004) showed that exposure to occupational noise of about $102 \mathrm{~dB}$ (A) intensity in a steel factory resulted to noise induced hearing loss in $84 \%$ of the examined workers. Also, Mndeme and Mkoma (2012) observed that industrial machine noise in a cement factory range from $58.08 \mathrm{~dB}(\mathrm{~A})$ to $104.82 \mathrm{~dB}(\mathrm{~A})$ and a total of $82.5 \%$ of workers had various health defects as a result of exposure to such noise. Another study (Atmaca et al., 2005) observed that noise in several industries ranged between 75 and $107 \mathrm{~dB}(\mathrm{~A})$ and resulted in several physical, physiological and psycho-social impacts on employees.

Wheat processing as an industrial activity involves wheat storage, separation, conditioning, blending, grinding, sieving, and addition of additives. Machines such as Combined-cleaners, Drum sieve, Magnetic separator, Rollers, Scourer, Turbo-Sifters, High Pressure blower, and Air-lock are used in the production line. Each of these machines generates different levels of noise and their combined effect may be harmful to workers. Therefore the aim of this study is to assess the level of noise in typical wheat processing factory, the likely effects and audiometric status of employees.

\section{MATERIAL AND METHODS}

The study was conducted at a wheat processing factory in Ilorin, North Central Nigeria. The factory has about 100 employees and processes wheat into flour, semolina and bran. Noise levels were measured between November 2013 and January 2014 during working hours. A portable digital datalogging sound level meter; HD600 manufactured by Extech Inc., USA, set to the A-weighting scale, was used to measure noise levels at predetermined sampling points within the factory. The equipment meets Type 2 requirements of American National Standards Institute (ANSI S1.4) and International Electrotechnical Commission (IEC 61672-1). Noise measurement was taken in triplicates around machines for 8 hours, at various sections and in 
administrative offices. At the end of each experiment, the obtained data was downloaded to a personal computer and analyzed.

On the other hand, subjective assessment was undertaken using a World Health Organization (WHO) standard questionnaire to obtain data on physiological and psychological effects of noise on workers. The questionnaire was filled by each worker under close supervision to avoid influence from coworkers. Information such as demographics, nature of work, noise annoyance and effects, hearing ability, use of protective devices (e.g. earplugs and earmuffs) were among the questions included in the questionnaire. Also, audiometric examination was carried out on workers in the factory to know their hearing ability. Diagnostic audiometer (AD229e) which is designed for diagnosing hearing loss was used for the examination. Output and specifics of this equipment are based on the test characteristics defined by the user, and may vary depending on environmental and operating conditions.

\section{RESULTS AND DISCUSSION}

The average, equivalent, minimum and maximum noise level at different sections in the wheat processing factory is shown in Table 1 . The maximum recorded noise level of $100.9 \mathrm{~dB}$ (A) was obtained at the Flour Bagging and Stitching Section. This value is above the maximum permissible noise level of $85 \mathrm{~dB}(\mathrm{~A})$ described by the National Environmental Standards and Regulations Enforcement Agency (NESREA, 2009). The flour bagging and stitching section houses automated packing and stitching machines which are noisy.

It was also found that in individual machine noise measurements, the magnetic drum, air lock, scourer, rollers, high pressure blower, combined-cleaner, and sieve generated noise which was greater than the recommended limit of $85 \mathrm{~dB}(\mathrm{~A})$ by $99.4,96.1,90.7$, 86.4, 75.4, 44.0 and 3.6\% respectively. The indoor noise in the Maintenance Office, Quality Control Laboratory, Production Office, Bakery section, Bran bagging and Stitching section, and Control Room are within permissible limits.

Table 2 shows the response of workers to questions relating to occupational effects of noise. The claims by respondents are diverse and multifaceted. A total of $71.4 \%$ of respondents experience speech interference while $47.6 \%$ noticed a reduction in hearing over the course of the day. Also, 38.1, 14.3, $61.9,14.3,38.1$ and $14.3 \%$ complain of tinnitus, heaviness in ear at the end of work shift, diplacusis, nervousness and annoyance, blurred hearing, and long term hearing problem respectively. These ailments are likely to cause absenteeism or lowered productivity.

The summary of audiometric examination of workers in the factory which was derived from individual worker's audiogram is presented in Table 3. It was observed that $20 \%$ of the workers have hearing impairment in the left or right ear. However, irrespective of the position of the ear, a total of 33\% of the workers have hearing loss for some frequencies ranging from 0.125 to $8.0 \mathrm{kHz}$ which represents the speech spectrum of humans. Workers with mild hearing loss are unable to hear soft sounds but can hear normal conversation in a quiet environment while those with moderate hearing loss have difficulties in hearing normal conversation in a quiet environment. However, none of the examined workers has severe (71-90dBHL) or profound (above $90 \mathrm{dBHL}$ ) hearing loss.

Conclusion: The predominant noise sources in the factory are the High pressure blower, and Flour bagging and stitching section. A total of $74.4 \%$ of all the readings were found to be greater than the permissible noise limit of $85 \mathrm{~dB}(\mathrm{~A})$. Workers also have certain forms of physiological and psychological disorders related to noise. However majority of the examined workers $(67 \%)$ have normal hearing in both left and right ear. From the prevailing measured noise in this factory, Class-5 personal hearing protectors should be provided to all persons in the vicinity of the noise source. Also room acoustics should be upgraded to absorb some sounds transmitted from other sections to offices.

Acknowledgement: The authors appreciate and thank the management and staff of the wheat processing factory for their cooperation during this research. The assistance of Prof. A.A. Adegoke, the Director, Centre for Deaf and Supportive Services, University of Ilorin, is also appreciated. 
Table 1: Noise levels around machines in various sections and offices

\begin{tabular}{lllll}
\hline Machines/sections/offices & $\begin{array}{l}\mathrm{L}_{\min } \\
\mathrm{dB}(\mathrm{A})\end{array}$ & $\begin{array}{l}\mathrm{L}_{\max } \\
\mathrm{dB}(\mathrm{A})\end{array}$ & $\begin{array}{l}\mathrm{L}_{\mathrm{Aeq}} \\
\mathrm{dB}(\mathrm{A})\end{array}$ & $\begin{array}{l}\%> \\
85 \mathrm{~dB}(\mathrm{~A})\end{array}$ \\
\hline Magnetic Drum & 84.9 & 89.6 & 88.45 & 99.4 \\
Air-lock & 63 & 96.8 & 94.6 & 96.1 \\
Rollers & 83.9 & 92.9 & 89.13 & 86.4 \\
High pressure Blower & 56 & 99.4 & 93.42 & 75.4 \\
Sieve & 58.7 & 85.6 & 78.21 & 3.6 \\
Combined-Cleaner & 56.4 & 90.5 & 84.81 & 44.0 \\
Scourer & 83.7 & 91.9 & 87.73 & 90.7 \\
Turbo Sifter & 79.2 & 85 & 82.38 & 0.0 \\
Flour bagging and stitching section & 72 & 100.9 & 85.49 & 10.3 \\
Bran bagging and Stitching section & 73 & 81.7 & 78.74 & 0.0 \\
Quality control laboratory & 58.7 & 73.6 & 64.72 & 0.0 \\
Bakery section & 61.4 & 74.5 & 66.49 & 0.0 \\
Maintenance office & 66.9 & 82.5 & 71.54 & 0.0 \\
Production's head office & 59.9 & 70.9 & 61.95 & 0.0 \\
Control room & 66.1 & 80.0 & 70.65 & 0.0 \\
\hline
\end{tabular}

Table 2: Observed physiological and psychological effects

\begin{tabular}{lc}
\hline Characteristics & $\begin{array}{c}\text { Percentage } \\
(\%)\end{array}$ \\
\hline Speech interference & 71.4 \\
Reduction in hearing & 47.6 \\
Tinnitus (ringing in ear) & 38.1 \\
Heaviness in ear & 14.3 \\
Diplacusis & 61.9 \\
Nervousness and & 14.3 \\
annoyance & \\
Blurred hearing & 38.1 \\
Long term hearing problem & 14.3 \\
\hline
\end{tabular}

Table 3: Summary of audiometric examination reports

\begin{tabular}{llll}
\hline $\begin{array}{l}\text { Ear } \\
\text { position }\end{array}$ & $\begin{array}{l}\text { Degree of hearing loss } \\
(\mathrm{dBHL})\end{array}$ & $\begin{array}{l}\text { Percentage } \\
(\%)\end{array}$ & $\begin{array}{l}\text { Diagnosis } \\
\text { remark }\end{array}$ \\
\hline Right & $0-25$ & 80 & Normal hearing \\
Right & $26-40$ & 20 & Mild hearing loss \\
Left & $0-25$ & 80 & Normal hearing \\
Left & $26-40$ & 10 & Mild hearing loss \\
Left & $41-70$ & 10 & Moderate hearing loss \\
dBHL = Decibel Hearing Level & & \\
\hline
\end{tabular}

\section{REFERENCES}

Ahmed, HO; Dennis, JH; Badran, O; Ismail, M.; Ballal SG; Ashoor, A; Jerwood, D (2001). Occupational noise exposure and hearing loss of workers in two plants in Eastern Saudi Arabia. Ann Occup Hyg 45 (5): 371 - 380.

Atmaca, E; Peker, I; Altin, A (2005). Industrial noise and its effects on humans. Polish J Environ Stu 14 (6), $721-726$.

Harmadji, S; Kabullah, H (2004). Noise induced hearing loss in steel factory workers. Folia Medica Indonesiana 45 (5): 171 - 174.
Mndeme,FG; Mkoma, SL (2012). Assessment of work zone noise levels at a cement factory in Tanga, Tanzania. Ethiopian J Environ Stu and Manag 5 (3): 225 - 231.

NESREA (2009). National Environmental (Noise Standards and Control) Regulations, 2009. Federal Republic of Nigeria Official Gazette, Vol. 96, No. 67, S.I. No. 35, FGP 104/102009/1,000 (OL 60), The Federal Government Printer, Nigeria.

WHO (2011). Burden of Disease from Environmental Noise: Quantification of Healthy Life Years Lost in Europe. World Health Organization Regional Office for Europe, Denmark 